Témoigner Témoigner. Entre histoire et mémoire

Getuigen Revue pluridisciplinaire de la Fondation Auschwitz

$122 \mid 2016$

Révisionisme et négationisme

\title{
Benoît Rayski, Stèle pour le sous-lieutenant Grunberg, lycéen guillotiné par Pétain
}

Jean-Pierre Pisetta

\section{OpenEdition}

1 Journals

Édition électronique

URL : https://journals.openedition.org/temoigner/4783

DOI : 10.4000/temoigner.4783

ISSN : 2506-6390

Éditeur :

Éditions du Centre d'études et de documentation Mémoire d'Auschwitz, Éditions Kimé

Édition imprimée

Date de publication : 2 mai 2016

Pagination : 177-178

ISSN : 2031-4183

Référence électronique

Jean-Pierre Pisetta, "Benoît Rayski, Stèle pour le sous-lieutenant Grunberg, lycéen guillotiné par Pétain »,

Témoigner. Entre histoire et mémoire [En ligne], 122 | 2016, mis en ligne le 30 septembre 2021, consulté le 11 janvier 2022. URL : http://journals.openedition.org/temoigner/4783 ; DOI : https://doi.org/ 10.4000/temoigner.4783

Ce document a été généré automatiquement le 11 janvier 2022.

Tous droits réservés 


\title{
Benoît Rayski, Stèle pour le sous- lieutenant Grunberg, lycéen guillotiné par Pétain
}

\author{
Jean-Pierre Pisetta
}

\section{RÉFÉRENCE}

Benoît Rayski, Stèle pour le sous-lieutenant Grunberg, lycéen fusillé par Pétain, Perpignan, éditions du Rocher, 2014, 126 p.

1 Les décapitations - opérées sous le sceau de l'extrémisme - du guide de haute montagne Hervé Gourdel et du chef d'entreprise Hervé Cornara ont à juste titre suscité l'horreur - entre autres - des Français. On avait pourtant, dans l'Hexagone, pendant près de deux siècles et jusqu'il y a moins de cinquante ans, coupé des têtes pour le bien de la nation. Isidore David Grunberg était un de ces - tout jeunes - suppliciés.

2 Il était né à Lwów, en Pologne, en 1923. Ses parents, des Juifs pauvres, s'y étaient établis peu avant sa naissance, mais n'y étaient guère restés, préférant, grâce à de faux papiers, chercher un sort meilleur dans le pays des droits de l'homme, pays qui verrait bientôt les droits de l'homme juif se réduire comme une peau de chagrin.

3 Après avoir durement gagné son pain, le père Grunberg parvint à donner une éducation respectable à son Isidore qui entra au Lycée Voltaire, établissement réputé de leur arrondissement parisien.

4 Sauf que le jeune Grunberg se rapproche peu à peu de communistes qui vont l'entraîner sur une pente le glissant jusqu'à sa perte. En novembre 1940, à la suite d'une distribution, devant l'école, de tracts attaquant violemment le maréchal Pétain, il est recherché par la police, entre dans la clandestinité et est exclu de l'institution.

5 À peine un an plus tard, le 7 janvier 1942, alors qu'il faisait un repérage devant un garage qui devait être la cible d'un prochain attentat, Isidore est interpellé par un agent 
qui finira sous ses balles. La mort du policier Patrick Lécureuil sera rédhibitoire : le «terroriste judéo-bolchévique » Isidore David Grunberg ne bénéficiera, malgré ses seuls 19 ans d'âge, d'aucune clémence et sera guillotiné le 8 août 1942.

6 Benoît Rayski pose ainsi une "stèle " sur la figure de ce jeune résistant dont la mémoire avait été jetée aux oubliettes de l'Histoire. Son père, qui avait survécu à la guerre - l'auteur ne nous apprend toutefois pas comment il a échappé à l'Holocauste avait bien obtenu, en 1962, que son fils fût nommé, à titre posthume, "souslieutenant » de la Résistance, mais ce « certificat » était destiné à végéter dans un tiroir et Benoît Rayski regrette que le parti communiste n'ait jamais œuvré pour que l'un de ses adeptes, à l'instar d'autres jeunes victimes du nazisme et du racisme collaborationniste, n'ait son nom gravé sur une plaque, à un coin de rue, sur une place, ou dans la liste des (autres) Juifs martyrs du Lycée Voltaire...

7 Ce livre utile, voire indispensable, qui sauve de l'oubli ce tout jeune homme dont la seule erreur, dans la vie, fut d'avoir dégainé trop vite et tiré inconsidérément, aurait néanmoins mérité une énième relecture avant d'être mis sous presse. On comprend que Benoît Rayski n'ait guère de sympathie pour le « fonctionnaire en charge d'exécuter les arrêts criminels ", autrement dit pour le bourreau qui décapita Isidore David Grunberg, mais l'appeler Jules-Henri Desfourneaux dans le chapitre de présentation au début du livre et Georges-Henri Desfourneaux dans celui de la décapitation n'est pas un gage de sérieux documentaire. De même, la «mère maquerelle »-guère plus appréciée que le bourreau - qui déposera dans l'affaire du policier abattu est appelée tantôt Mlle Guileiou, tantôt Mlle Guigliou.

8 Il faut dire que les autorités françaises n'ont pas fait preuve de plus de cohérence : la condamnation à la peine de mort datée du 15 juin 1942 est requise, par le Parquet du Tribunal de la Seine, pour Isidore non pas Grunberg mais Grünberg, alors que la "médaille de la résistance française » décernée au jeune condamné, à titre posthume, en 1971 porte le nom d'Isidore Grinberg.

Il s'agit là, cela va de soi, de détails qui n'enlèvent rien à la louable intention de Benoît Rayski : sa "stèle ", à défaut de se dresser dans l'espace public, commémorera à jamais le souvenir du jeune Isidor (en polonais, son vrai prénom) dans l'esprit de ses lecteurs. 